\title{
Using Credit Cards to Streamline the Use of Resources
}

\author{
Farideh Moradi ${ }^{1}$, Mohammad Mohseni ${ }^{2}$, Majid Nakhaee ${ }^{3}$, Ali Soroush ${ }^{{ }^{*}}$ \\ ${ }^{1}$ Life Style Modification Research Center, Imam Reza Hospital, Kermanshah University of Medical Sciences, \\ Kermanshah, Iran \\ ${ }^{2}$ Health Management and Economics Research Center, Iran University of Medical Sciences, Tehran, Iran \\ ${ }^{3}$ School of Health Management and Information Sciences, Iran University of Medical Sciences, Tehran, Iran
}

*Corresponding Author: Ali Soroush, Life Style Modification Research Center, Imam Reza Hospital, Kermanshah University of Medical Sciences, Kermanshah, Iran. Tel: +98-83-34280886, Email: ali.soroush.mhr@gmail.com

Received March 12, 2018; Accepted April 22, 2018; Online Published May 1, 2018

\section{Dear Editor,}

Health organizations are one of the most important organizations of every country. The responsibility and duty of such organizations are to supply, maintain, and improve the individuals of society. The hospital as a health organization has long been one of the most important medical service providers. ${ }^{1}$ Increasing health system costs all over the world have become a main concern of health system managers and decision makers. ${ }^{2}$

The health system of Iran, like others, faces the challenge of major increases in costs. While the total index of expenses in Iran has become 30 times greater in the past 20 years, expenses in the health sector have increased to a figure 71 times higher. ${ }^{3}$ One noteworthy point is that hospitals in which are regarded as the biggest and the most expensive operational unit in healthcare organization including 50\% of the total costs and allocating about $80 \%$ of educated medical courses staffs to themselves. ${ }^{1}$

Evidently, all sectors of the health system are affected by economic problems, some of which originate in the structural and internal problems of each section. Some other health sections have problems imposed upon them, and some problems originate from the macroeconomic policies of the health system. ${ }^{4}$ According to a WHO report, general hospitals allocate $80 \%$ of health system resources to themselves, while producing only $20 \%$ of the output of this section. ${ }^{5}$ Although hospitals allocate high expenses to themselves, a large quota of costs occurring in hospitals are due to a lack of good performance. Some factors, such as the inappropriate admission of patients, misallocation of sources, reworking and other factors, play significant roles in creating costs. ${ }^{6}$

One way to increase costs is to improperly use or waste resources. To solve this problem, it is suggested that the amount of supplies required in hospital sectors and units over a one-month period be estimated based on the statistics, and then the costs can be better determined. The estimated amount should then be given to section managers in the form of a credit card. Purchasing the necessary materials should be delegated to the officials and relevant authorities on a monthly basis, and the surplus should be distributed to staff members or different wards as encouragement. This can be considered as a motivation strategy for individual efficient use of resources.

\section{Authors' Contributions}

All authors contributed equally to this research.

\section{Conflict of Interest Disclosures}

The authors declare that there is no conflict of interest..

\section{Ethical Approval}

Not applicable.

\section{References}

1. Salmanzadeh $\mathrm{H}$. Hospital administration \& efficiency at teaching hospitals affiliated with Iran University of Medical Sciences. Journal of Health Administration. 2001;4(8):1-11. [Persian].

2. Walley T, Haycox A, Boland A. Pharmacoeconomics. Philadelphia: Elsevier Health Sciences; 2004:11-12.

3. The main economic indicators. Central Bank of Islamic Republic of Iran website. http://www.cbi.ir/. Accessed May 5, 2012. Published 2012.

4. Davari M, Walley T, Haycox A. The Iranian health insurance system; past experiences, present challenges and future strategies. Iran J Publ Health. 2012;41(9):1-9.

5. Castano R, Bitran RA, Giedion U. Monitoring and Evaluating Hospital Autonomization and Its Effects on Priority Health Services. Partners for Health Reformplus. Bethesda: Abt Associates Inc; 2004.

6. Karami matin B. A Study of General Teaching Hospitals Efficiency at Kermanshah University of Medical Sciences. Journal of Health Administration. 2001;4(8):30-39. [Persian].

Copyright (C) 2018 The Author(s). This is an open-access article distributed under the terms of the Creative Commons Attribution License (http:// creativecommons.org/licenses/by/4.0), which permits unrestricted use, distribution, and reproduction in any medium, provided the original work is properly cited. 